\title{
Phylogeographic and phenotypic assessment of a basal haplochromine cichlid fish from Lake Chila, Zambia
}

\author{
B. Egger $\cdot$ Y. Klaefiger $\cdot$ A. Indermaur $\cdot$ S. Koblmüller $\cdot$ \\ A. Theis - S. Egger - T. Näf • M. Van Steenberge • \\ C. Sturmbauer $\cdot$ C. Katongo $\cdot$ W. Salzburger
}

Received: 24 February 2014 / Accepted: 19 May 2014 / Published online: 1 July 2014

(C) Springer International Publishing Switzerland 2014

\begin{abstract}
The basal haplochromine genus Pseudocrenilabrus comprises three valid species, although the current taxonomy most probably underestimates species richness. Previous phylogeographic studies on the $P$. philander species complex revealed a clear structuring of populations, shaped by river capture events. Here we report the discovery of $P$. cf. philander in Lake Chila, a small lake south of Lake Tanganyika. We were interested whether discrete
\end{abstract}

Guest editors: S. Koblmüller, R. C. Albertson, M. J. Genner, K. M. Sefc \& T. Takahashi / Advances in Cichlid Research: Behaviour, Ecology and Evolutionary Biology

Electronic supplementary material The online version of this article (doi:10.1007/s10750-014-1919-0) contains supplementary material, which is available to authorized users.

B. Egger $(\bowtie) \cdot$ Y. Klaefiger · A. Indermaur .

A. Theis · S. Egger · T. Näf · W. Salzburger ( $\square)$

Zoological Institute, University of Basel, Vesalgasse 1, 4051 Basel, Switzerland

e-mail: bernd.egger@unibas.ch

W. Salzburger

e-mail: walter.salzburger@unibas.ch

S. Koblmüller · C. Sturmbauer

Department of Zoology, Karl-Franzens University of

Graz, Universitatsplatz 2, 8010 Graz, Austria

M. Van Steenberge

Zoology Department, Ichthyology, Royal Museum for Central Africa, Leuvensesteenweg 13, 3080 Tervuren, Belgium morphs, similar to what has been found in Lake Mweru and the Lunzua River, were present in Lake Chila. We evaluated the phenotypic variability of the population in relation to other lacustrine and riverine populations by quantifying colouration and body shape. To place the specimens in a phylogeographic framework, we inferred a phylogeny based on the most variable part of the mitochondrial control region. We found two divergent mtDNA lineages in Lake Chila and tested for population structure and admixture between the lineages using microsatellite data. Our study reveals a complex phylogeographic pattern and demonstrates admixture of distant mtDNA lineages in Lake Chila, producing a hybrid swarm with substantial phenotypic variability. Unlike in Lake Mweru, Pseudocrenilabrus has not diversified further into discrete morphs in Lake Chila, probably because

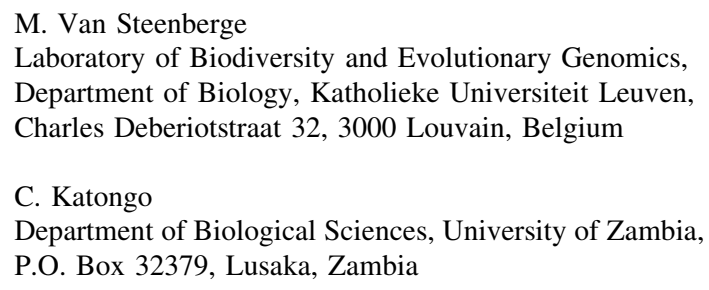


of the long-term instability of the lake and the presumed recency of the admixture event.

Keywords Phylogeography · Nuptial colouration · Pseudocrenilabrus $\cdot$ Hybridization

\section{Introduction}

Cichlid fishes from the East African Great Lakes, Tanganyika (LT), Malawi (LM) and Victoria (LV), are well-known model systems for studying the mechanisms underlying adaptive radiation and explosive speciation (see e.g. Kocher, 2004; Salzburger, 2009; Santos \& Salzburger, 2012). Within African cichlids, the Haplochromini stand out as the most species-rich lineage, comprising the species flocks of LM and LV, the Tropheini from LT, as well as riverine and lacustrine species from northern, eastern, southern and central Africa and the levant (Turner et al., 2001; Verheyen et al., 2003; Joyce et al., 2005; Salzburger et al., 2005; Koblmüller et al., 2008a). The majority of haplochromine cichlids belongs to the derived 'modern' clade (as defined in Salzburger et al., 2005), the members of which are mostly lacustrine, characterized by a pronounced sexual colour dimorphism with typically brightly coloured males and inconspicuous females, a polygynandrous mating system with maternal mouthbrooding, as well as egg-spots on the anal fin of males. The cichlid fauna of many rivers and smaller lakes, especially in central and southern Africa, is typically dominated by more basal haplochromine lineages. These lineages are considered comparably species poor, which has been explained by the lack of ecological opportunity in temporally unstable riverine ecosystems (Joyce et al., 2005). One of these basal riverine haplochromine lineages is represented by the genus Pseudocrenilabrus, which is distributed across many river systems and ichthyogeographic regions in northern, eastern, central and southern Africa (Skelton, 1991). The genus currently comprises three valid species, P. multicolour (two subspecies: P. m. multicolour and $P$. m. victoriae), $P$. nicholsi and $P$. philander (three subspecies: P. p. dispersus, P. p. luebberti and $P$. p. philander), although the current taxonomy likely underestimates species richness (Twentyman-Jones et al., 1997; Katongo et al., 2005; Stelkens \& Seehausen, 2009). Pseudocrenilabrus are all considered generalist species, typically inhabiting calm parts of rivers, swamps and flooded areas (Greenwood, 1989). Males of the genus Pseudocrenilabrus generally show less elaborate nuptial colouration compared to 'modern' haplochromines and lack egg-spots, but most populations feature a red to orange blotch on the posterior margin of their anal fin.

The phylogeographic relationships within the genus Pseudocrenilabrus have so far mainly addressed the $P$. philander species complex in southern Zambian rivers. Two previous studies revealed a clear structuring of populations, possibly shaped by tectonic movements that allowed for past temporal connections between watersheds (Katongo et al., 2005; Koblmüller et al., 2012). Based on sequences of the most variable part of the mitochondrial control region (d-loop), Katongo et al. (2005) identified four distinct clades: the Chambeshi-Bangweulu clade, the Lake Mweru clade, the Lunzua clade and the Kafue-Zambezi clade. In more recent studies, Koblmüller et al. (2008a, 2012) included a previously undescribed haplochromine species from the Lufubu River ( $P$. sp. 'Lufubu A'), which turned out as the most basal lineage in the genus. $P$. sp. 'Lufubu A' is found in sympatry with another Pseudocrenilabrus that represents a fifth lineage within the $P$. philander species complex ( $P$. sp. 'Lufubu B'; Koblmüller et al., 2012). Despite the existence of several subspecies and many geographically separated, often morphologically distinct populations (Greenwood, 1989; Katongo et al., 2005), the genus was considered species poor in comparison to other riverine taxa (Skelton, 1994). However, Koblmüller et al. (2008b) described a population from the upper Lunzua River that contains two (blue and yellow) colour morphs sharing a single mitochondrial haplotype, but showing weak differentiation at nuclear markers suggesting that they might be undergoing incipient speciation. In addition, Stelkens and Seehausen (2009) reported the occurrence of at least 13 distinct morphs of Pseudocrenilabrus cf. philander in Lake Mweru. The morphs were assigned to two divergent mitochondrial lineages, of which the more frequent one diversified with respect to eco-morphology and nuptial colouration. In mate choice experiments, it was shown that the degree of divergence between morphological traits, but not genetic distance, was associated with the level of reproductive isolation between morphs (Stelkens \& Seehausen, 2009). The existence of a small adaptive radiation in Lake Mweru 


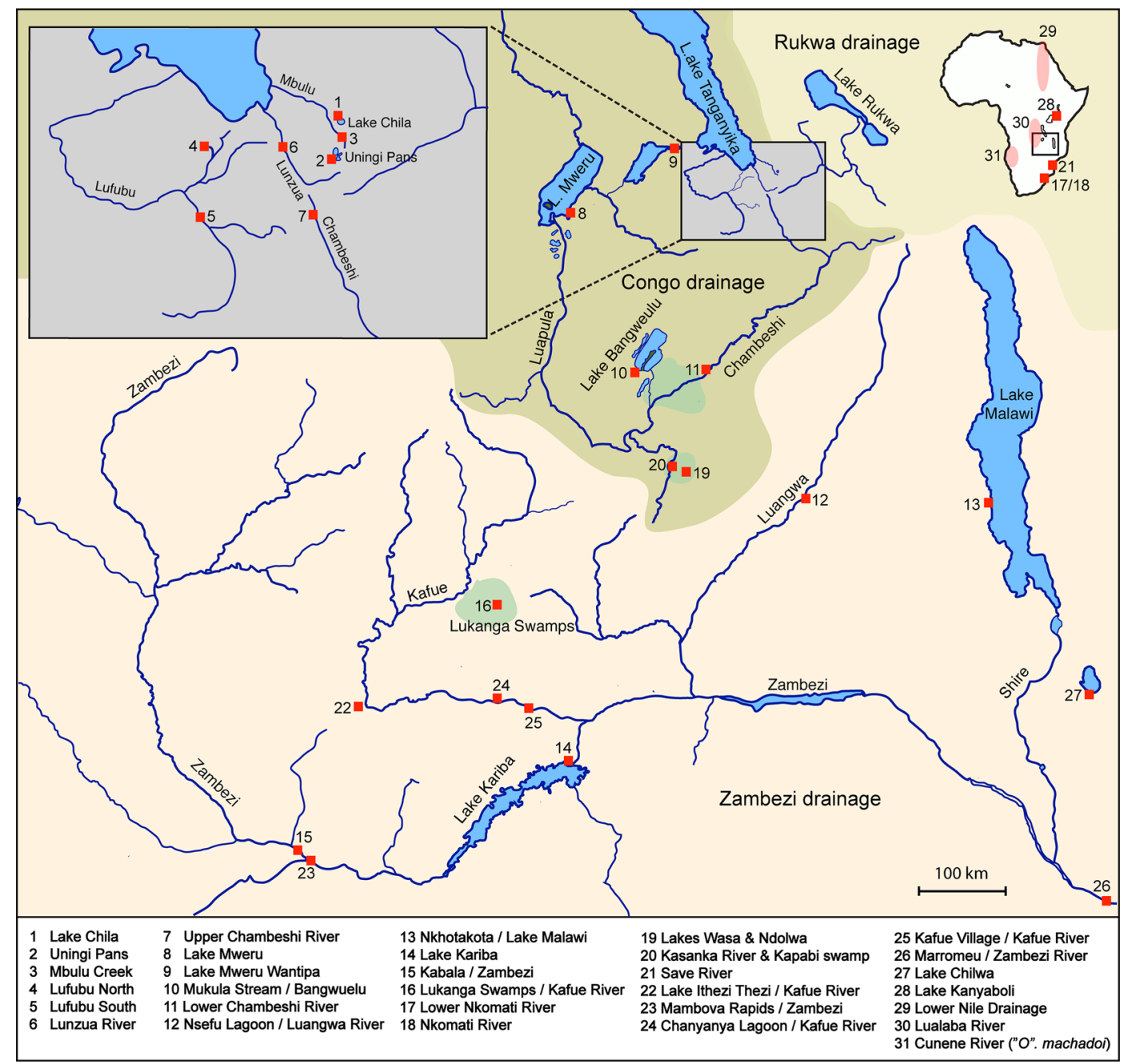

Fig. 1 Simplified map of the major water bodies in our study area showing the 28 sampling sites (red squares). Locations 29-31 roughly indicate the natural range of specimens acquired from the aquaria trade or where the exact location was unknown (translucent red areas). Dark green patches indicate swampy

suggests that Pseudocrenilabrus are more likely to diversify in a stable heterogeneous (lake) environment, providing more ecological opportunity as compared to rivers (see e.g. Schluter, 2000; Wagner et al., 2012).

During a field trip in February 2012, we discovered a population of $P$. cf. philander in Lake Chila, a small (approximately 1,200 $\mathrm{m}$ long and $900 \mathrm{~m}$ wide) and shallow (maximum depth $=4 \mathrm{~m}$ ) but permanent lake $20 \mathrm{~km}$ south of Lake Tanganyika (Fig. 1). Apart from $P$. cf. philander, the lake harbours a cichlid fauna typical for the Chambeshi, Zambezi and the Zambian/ Congo watersheds (Serranochromis angusticeps, S. areas. Different background colours designate the major drainages indicated in the figure, namely Zambezi, Congo and Rukwa (including eastward draining rivers). Sampling site 19 and 20 each designate two sites that are very close together and belong to the same system

robustus, S. thumbergi, Tilapia sparmanii, Oreochromis macrochir) and Astatotilapia burtoni from the LT basin (see also Skelton, 1993). Pseudocrenilabrus from this population showed phenotypes distinct from other populations belonging to the $P$. philander species complex, with deeper bodies compared to nearby riverine populations and very elaborate colour patterns in males. We evaluated the phenotypic variability of the Lake Chila population in relation to other lacustrine (Mweru-Wantipa) and riverine (Lunzua and Chambeshi) populations by quantifying male nuptial colouration and body shape based on 
standardized photographs. To place the Lake Chila specimens in a phylogeographic context, we reconstructed a phylogeny based on the most variable part of the mitochondrial control region using available Pseudocrenilabrus sequences from GenBank and additional samples recently collected from the area (Fig. 1). Interestingly, we found that two divergent mtDNA lineages were present in the small lake and further tested for population structure (in relation to neighbouring riverine populations) and admixture between the two mtDNA lineages using microsatellite data.

\section{Materials and methods}

\section{Sampling}

Sampling of Pseudocrenilabrus spp. was carried out during several field trips to Zambia between September 2003 and February 2012 (see Fig. 1; Tables S1, S2 and S3 for details on sample size and locations). Specimens were collected using gill nets and hook and line fishing under the permission of the Lake Tanganyika Research Unit, Department of Fisheries, Ministry of Agriculture and Livestock, Republic of Zambia. Fish were anaesthetized using clove oil (2-3 drops clove oil per litre water) and photographed in a standardized manner for later colour pattern and geometric morphometric analyses. Fin clips were taken from the specimens directly in the field and subsequently preserved in $96 \%$ ethanol for further whole genomic DNA extraction. From each sampling location, at least one whole specimen was preserved in $96 \%$ ethanol.

\section{Male body colouration}

To evaluate differences in nuptial colouration within and between populations, we used standardized photographs of males from Lake Chila $(n=49)$, Lunzua River $(n=7)$, Mbulu Creek $(n=2)$, Lufubu River $(n=3)$, Chambeshi River $(n=2)$, Lake MweruWantipa $(n=15)$ and the Uningi Pans $(n=3)$ (Table S3) to extract nine features related to colouration (see Salzburger et al., 2006): anal fin colour (red/yellow/redyellow/none); anal fin blotch colour and presence (orange/red/none); dorsal fin colouration (black-red/ red-grey/none); pelvic fin colouration (intensity of black stripe); caudal fin pattern (spotted/half spotted); dorsal body colouration (bluish/yellowish/blue-yellowish/none); central body colouration (bluish/yellowish/ blue-yellowish/none); ventral body colouration (bluish/ yellowish/blue-yellowish/none) and eye bar presence. Characters were translated into a categorical data matrix and analysed in a Multiple Correspondence Analysis (MCA) in R (v.3.0.3, R Development Core Team, 2014; package FactoMineR, Husson et al., 2014).

\section{Body shape}

The photographs of males from Lake Chila $(n=49)$, Lunzua River ( $n=18)$, Lufubu River $(n=5)$, Chambeshi River $(n=2)$ and Lake Mweru-Wantipa $(n=14)$ (Table S3) were used to obtain data for the geometric morphometric analyses by recording the coordinates of 17 homologous landmarks (for details see Muschick et al., 2012) using TPSDIG2 (v.2.11; Rohlf, 2008). The $x$ and $y$ coordinates were transferred to the program MoRPHOJ (v.1.05f; Klingenberg, 2011) and superimposed with a Procrustes generalized least squares fit (GLSF) algorithm to remove all non-shape variation (Rohlf \& Slice, 1990). Additionally, the data were corrected for allometric size effects by using the residuals of the regression of shape on centroid size for further analyses. A canonical variate analysis (CVA; Mardia et al., 1979) was used to assess shape variation among the populations. The mean shape distances of the $\mathrm{CV}$ analysis were obtained using permutation tests (10,000 replications). Additionally, a PCA was conducted to assess within-population variance in body shape for Lake Chila only.

\section{Molecular methods}

Total DNA was extracted from fin clips preserved in ethanol applying a proteinase $K$ digestion followed by either a high-salt (Bruford et al., 1998) or a Magna Pure extraction using a robotic device (Magna Pure LC, Roche Diagnostics) and following the manufacturer's protocol (Roche, Switzerland).

We genotyped a total of 249 Pseudocrenilabrus specimens from the Lunzua River $(n=167 ; 73$ specimens sampled in 2004 partly used in Koblmüller et al., 2008b; 94 specimens sampled in 2010), Mbulu Creek ( $n=13$, sampled in 2010) and Lake Chila ( $n=69$, sampled in 2012) (see Table S2 for details) at 
5 microsatellite loci (HchiST46, HchiST94 (Maeda et al., 2008), UNH002 (Kellogg et al., 1995), Pmv3 and Pmv4 (Crispo et al., 2007)).

Fragment size calling was carried out on an ABI $3130 x l$ genetic analyser (Applied Biosystems) in comparison to the LIZ 500(-250) (Applied Biosystems) size standard. Genotypes were determined manually using Peak Scanner (v.1.0; Applied Biosystems), controlled and rounded to integers with the software TANDEM (v.1.09; Matschiner \& Salzburger, 2009). Structure (v.2.3.3; Pritchard et al., 2000) was then used to infer population structure (Markov chain Monte Carlo simulations were run for 500,000 replications, burn-in $=50,000$, admixture and correlated allele frequency options). Ten replicated simulations were performed for $K=1-8$ and the most likely number of genetic clusters was inferred using the $\Delta K$ method (Evanno et al., 2005) implemented in the software STRUCTURE HARveSTER (Earl \& von Holdt, 2012). Initially, we intended to genotype all 249 Pseudocrenilabrus spp. specimens with a larger set of microsatellite loci, but only 5 loci (see above) could be amplified in both the Lake Chila and the Lunzua River/Mbulu Creek samples. We, therefore, tested additional loci and selected, based on amplification success and the level of polymorphism, 7 loci for the Lake Chila subset (HchiST46, HchiST94 (Maeda et al., 2008), UNH002 (Kellogg et al., 1995), Pmv3, Pmv4 (Crispo et al., 2007), Ppun21 (Taylor et al., 2002), Pzeb3 (Van Oppen et al., 1997) and 6 loci for the Lunzua River/Mbulu Creek subset: (Pmv1, Pmv3, Pmv4, Pmv15 (Crispo et al., 2007), UNH989 and UNH002 (Kellogg et al. 1995)). We then performed StRUCtuRE analyses for the Lake Chila set and the Lunzua River/Mbulu Creek set separately to test for substructure within the two datasets. Conditions were the same as for the combined dataset, except the ten replicated simulations were performed for $K=1-5$ for Lake Chila and $K=1-10$ for Lunzua River/ Mbulu Creek. Genetic differentiation among all populations and between morphs within the Lunzua River samples, as well as between yellow morphs sampled in 2004 and 2010 (the low sample size of blue males from the same location did not allow for a contrast between different sample years) was estimated as $\theta_{\text {ST }}$ (Weir \& Cockerham, 1984) in ARLEQUIN (v.3.5; Excoffier \& Lischer, 2010) for both the dataset containing 5 loci and the Lunzua River/Mbulu Creek dataset with 6 loci.
We also determined the DNA sequence of the most variable part of the mitochondrial control region (359 bp in total) for 82 samples (see Table S1 for details) using published primers (L-ProF or L-Pro-F_Tropheus and TDK-D; Meyer et al., 1994; Lee et al., 1995; Koblmüller et al., 2011). Amplification and sequencing were performed as described elsewhere (Duftner et al., 2005; Koblmüller et al., 2011). The PCR fragments of the control region were purified using ExoSAP-IT (USB), directly sequenced with the BigDye sequencing chemistry (Applied Biosystems) and analysed on an ABI 3130xl genetic analyser (Applied Biosystems). Additionally, sequences of the most variable part of the mitochondrial control region for Pseudocrenilabrus spp. were obtained from GenBank (from Joyce et al., 2005; Katongo et al., 2005; Koblmüller et al., 2008a, 2012; Wagner et al., 2012; see Table S1 for details). Note that we also included 'Orthochromis' machadoi (Poll, 1967), since previous studies demonstrated the placement of this species within the genus Pseudocrenilabrus (see e.g. Koblmüller et al., 2008a). Together with the sequences from GenBank (total $n=155$ ), the mitochondrial DNA sequences were aligned in MAFFT v.6 (Katoh et al., 2002) under the FFT-NS-i option, i.e. with fast construction of an initial alignment followed by iterative refinement until convergence, with default gap penalties. Identical sequences were collapsed into haplotypes using DNA collapser implemented in the online tool FaBox (Villesen, 2007). Bayesian inference (BI) was carried out in MrBayes v.3.2.2 (Ronquist et al., 2012). Posterior probabilities were obtained from MCMC simulations in two independent runs (10 chains with 10 million generations each, chain temperature: 0.25 , trees sampled every 1,000 generations) using the best-fit model of molecular evolution as suggested by JModelTest (Posada, 2008). A $50 \%$ majority-rule consensus tree was constructed after a one million generation burn-in (chain stationarity and run parameter convergence were checked with Tracer v.1.6 (Rambaut et al., 2013), using posterior probability as a measure of clade support).

\section{Results}

Nuptial colouration

Results from the MCA on the colour matrix including all populations are shown in Fig. 2A. Dimension 1 


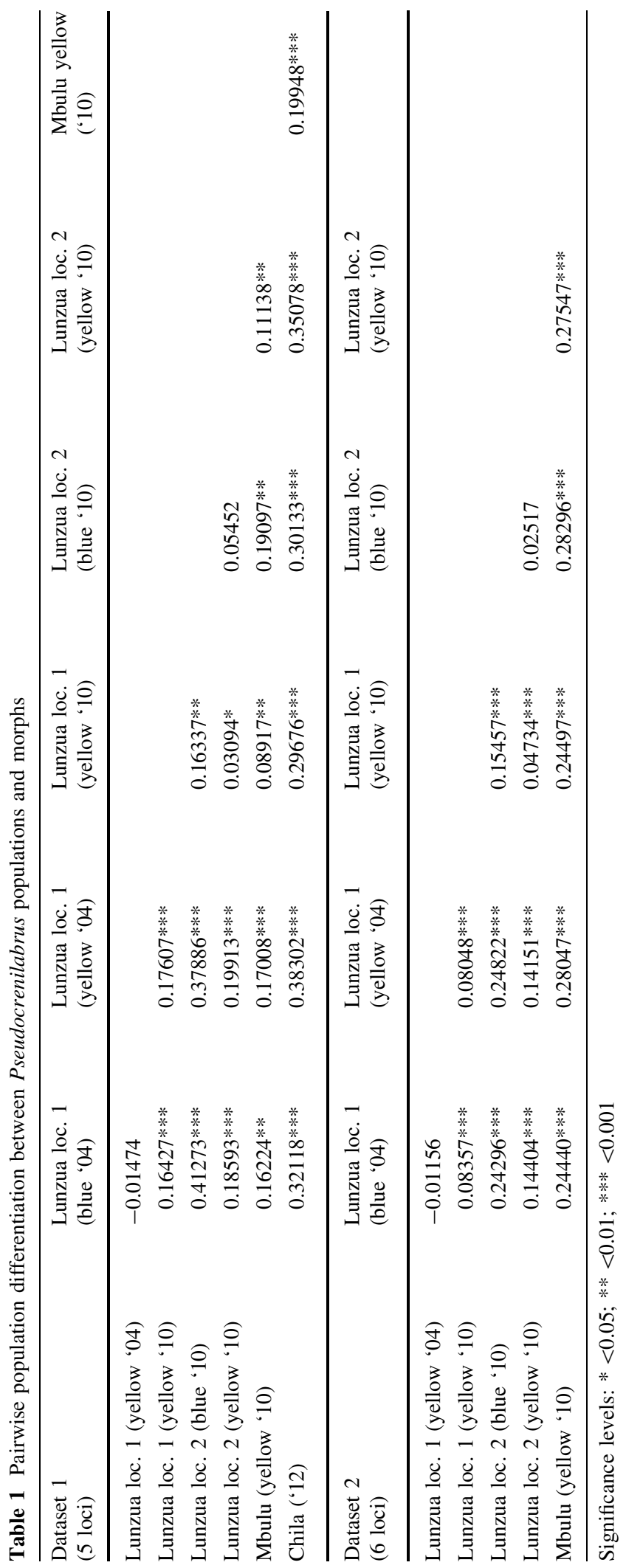




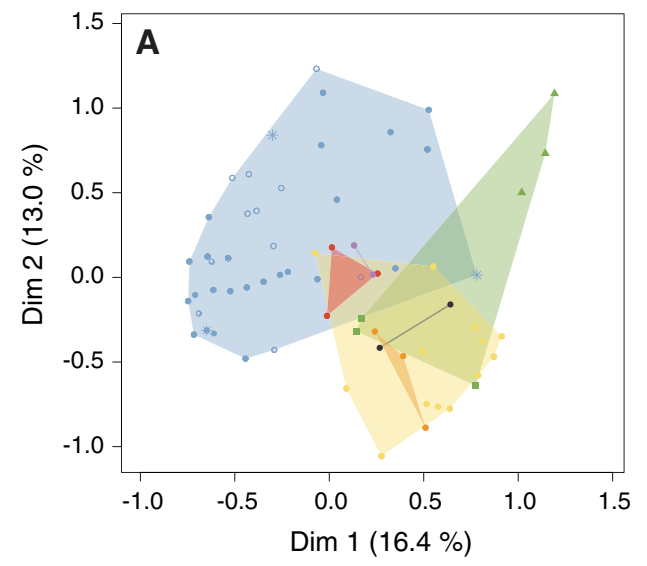

Fig. 2 A MCA based on nine male nuptial colouration traits. B CVA on male body shape based on 17 landmarks. Green triangles represent blue morphs and green squares yellow morphs from the Lunzua River (see Koblmüller et al. 2008b). Filled blue circles represent specimens assigned to the more

explained $16 \%$ and Dimension 2 explained $13 \%$ of the variation. The traits explaining most of the variation were related to anal fin, pelvic fin and central body colouration (data not shown). The samples from Lake Chila show the widest distribution in trait-space; however, there were no distinct phenotypic clusters detectable within the population, e.g. with respect to mitochondrial lineage assignment (Fig. 2A). Specimens from Lake Mweru-Wantipa and the Lunzua River partly overlapped with Lake Chila phenotypes. Within the males from Lunzua River, blue and yellow morphs were separated along the axis of Dimension 2. Yellow morphs from Mbulu Creek clustered with yellow morphs from the Lunzua River. Specimens from the Lufubu, Chambeshi and Uningi Pans fell within the distribution range of samples from Lake Mweru-Wantipa and values did not overlap with the majority of the Lake Chila specimens (Fig. 2A). While the separation of colour morphs within the Lunzua River population is mainly due to blue and yellow central body colouration and the presence/absence of an anal fin blotch, phenotypic variation in the Lake Chila population is due to a more complex interplay of several traits (e.g. colour of anal fin blotch; colour of anal, dorsal, pelvic and caudal fin; ventral, dorsal and central body colouration). The MCA restricted to specimens from Lake Chila did not detect any clustering that would indicate the presence of distinct morphs (Fig. S1A).

\section{Body shape}

The CVA of the overall body shape of the sampled populations revealed a significant differentiation between all populations (Fig. 2B; all pairwise population comparisons $P<0.05)$. The main body shape changes are described by canonical variate 1 (CV1, accounting for $53 \%$ of the variance), which shows mainly a prolongation of the head shape (with riverine Lunzua fish having longer heads and a more slender body shape), and CV2 (accounting for $32 \%$ of the variance) describing additional changes in body shape and mouth position (with fish from the Lufubu River having longer caudal peduncles, more slender bodies and a more inferior position of the mouth). The PCA on body shape for the Lake Chila population only did not detect any clustering that would indicate the presence of distinct morphs (Fig. S1B).

\section{Population structure}

Bayesian clustering with STRUCTURE of the combined dataset (including population samples from the Lunzua River, Mbulu Creek and Lake Chila) based on five microsatellites revealed a clear geographic pattern. The most likely number of $K=2$ separated one genotypic cluster comprising the two riverine populations from the cluster representing the Lake Chila stock (Fig. 3A). The separate STRUCTURE analysis for 
A
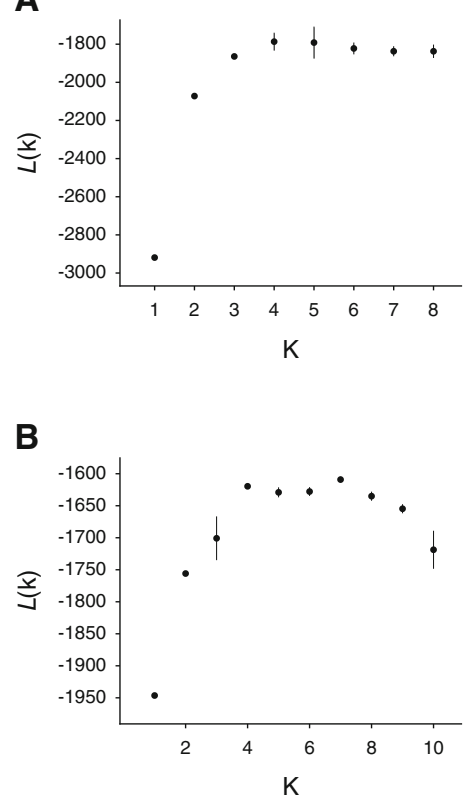
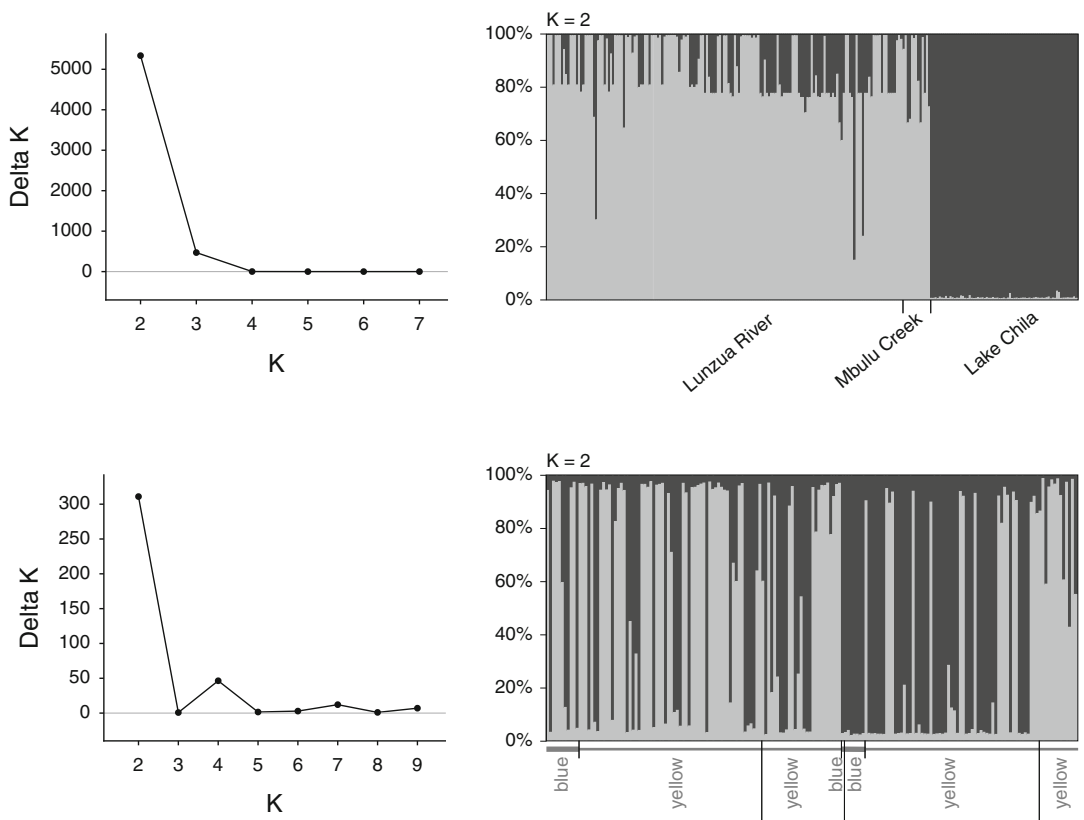

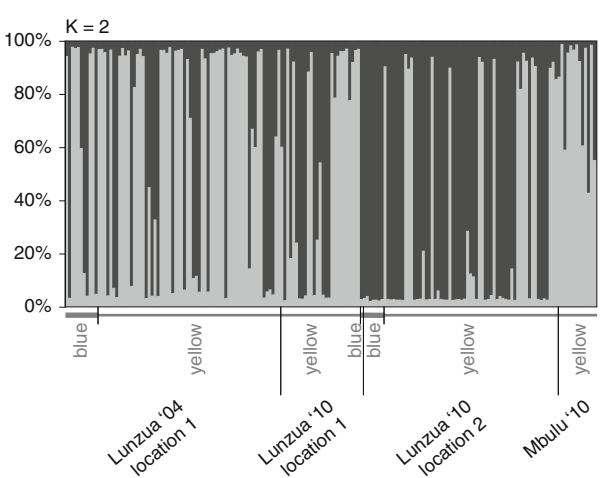

Fig. 3 Bayesian clustering analysis of Pseudocrenilabrus populations. A Dataset 1 (5 microsatellite loci) including samples from the Lunzua River, Mbulu Creek and Lake Chila. B Dataset 2 (6 microsatellite loci) including samples from the Lunzua River, Mbulu Creek and Lake Chila. Left mean

the Lake Chila fish with seven microsatellites did not detect additional substructure within the population ( $K=1$, data not shown). The analysis of the dataset comprising only the Lunzua River and Mbulu Creek specimens based on six microsatellites, resulted in the most likely number of $K=2$ (Fig. 3B). There was no clear genetic clustering detectable with regard to population or morph (Fig. 3B).

For the dataset including five microsatellite loci (Dataset 1, Table 1), pairwise comparisons revealed significant differentiation between morphs sampled in the years 2004 and 2010 (e.g. between yellow morphs from 2004 to 2010 from location 1) and between different sample locations (i.e. between Lunzua River locations 1 and 2; between Lake Chila and all other populations/morphs; between Mbulu Creek and all other populations/morphs), but not between blue and yellow morphs sampled within the same year.

Results from the Lunzua River/Mbulu Creek dataset (Dataset 2, Table 1) comprising 6 microsatellite loci (without the population from Lake Chila) are in likelihood $(L(K) \pm \mathrm{SD})$ over 10 runs assuming $K$ clusters. Middle $\Delta K$ statistic (see Evanno et al. 2005). Right Structure plots for the most likely number of genetic clusters $(K)$ as inferred from the $\Delta K$ statistic

line with those from the reduced dataset, with significant differentiation in all contrasts except between blue and yellow morphs sampled in the same year.

\section{Phylogeography}

Collapsing of sequences of the mitochondrial control region resulted in a total of 55 haplotypes (see Fig. 4; Table S1 for details). Our new BI phylogenetic reconstruction was largely in agreement with results from previous studies (Katongo et al., 2005; Koblmüller et al., 2012). The BI tree was rooted with $P$. sp. 'Lufubu A', which was identified as basal to all other Pseudocrenilabrus in previous phylogenetic studies (see Koblmüller et al., 2008a, 2012). Our new Lufubu River samples grouped with those downloaded from GenBank (Ht20 \& Ht34; Fig. 4). The remaining haplotypes clustered into two major mitochondrial lineages: One comprised the Kafue-Zambezi clade and specimens from the Upper Luapula area: Lake 


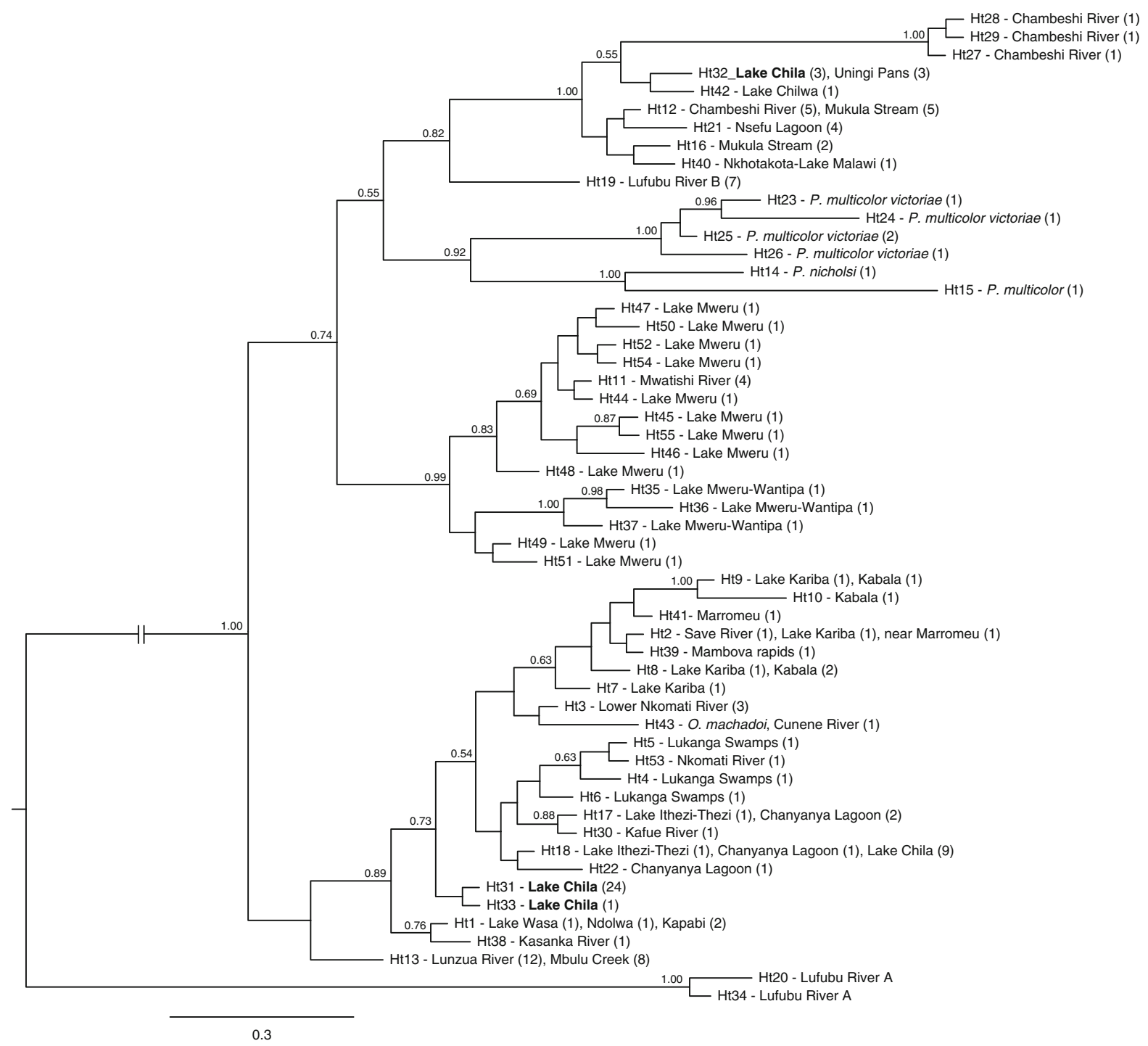

Fig. 4 Bayesian inference haplotype tree, rooted with Pseudocrenilabrus sp. 'Lufubu A'. Only posterior probabilities $\geq 0.50$ are shown

Wasa, Kasanka River, Ndolwa and Kapabi in Kasanka NP (Ht1 \& Ht38), as well as samples from further south (Cunene, Save and Nkomati basins). Our specimens from the Lunzua River and Mbulu Creek shared the haplotype with the previously published samples from the Lunzua River (Ht13) and formed the sister group to this lineage, although with very low posterior probabilities. 'Orthochromis' machadoi and, interestingly, two $P$. cf. philander haplotypes from Lake Chila (Ht31 \& Ht33) were resolved within the Kafue-Zambezi clade. In the other major mitochondrial lineage, $P$. sp. 'Lufubu B' (Ht19) was placed as sister group to the Chambeshi-Bangweulu clade. The newly sampled specimens from the Chambeshi River ( $\mathrm{Ht} 27, \mathrm{Ht} 28$ \& $\mathrm{Ht} 29)$ grouped in this clade, as well as new individuals from Lake Chila and the Uningi Pans (Ht32) plus the two specimens from the geographically distant Malawi drainage and nearby basins (Lake Chilwa, Ht42 \& Nkhotakota, Ht1). The samples from Lake Mweru-Wantipa (Ht35, Ht36 \& Ht37) grouped within the Lake Mweru clade. Specimens from the Lake Victoria region, the remainder of the Congo drainage and the Nile, comprising the species $P$. nicholsi and $P$. multicolour (including the subspecies 
P. m. victoriae), were placed as sister group to the Chambeshi-Bangweulu lineage, although with very low posterior probabilities.

\section{Discussion}

In this study, we reassessed the phylogeography of Pseudocrenilabrus in the watersheds of Zambia with a particular focus on a newly discovered lacustrine population of Pseudocrenilabrus cf. philander from Lake Chila, a small and shallow lake about $20 \mathrm{~km}$ south of LT. Males from this population displayed deeper bodies and more elaborate colour patterns compared to other known populations from the $P$. philander species complex. Interestingly, sequencing of the mitochondrial control region revealed the presence of two divergent mtDNA haplotype lineages in Lake Chila, with the more frequently sampled lineage (Ht31 \& Ht33, 90\% of Lake Chila mtDNA sequences) being associated with the Kafue-Zambezi clade, whereas the less frequent lineage (Ht32, $\sim 10 \%$ of Lake Chila mtDNA sequences) was placed within the Chambeshi clade (Fig. 4; Table S1). The exact origin of the two lineages remains unclear, and we cannot exclude the possibility that Pseudocrenilabrus, especially from the ZambeziKafue lineage, have been accidentally translocated in the course of a stocking event with Oreochromis macrochir (Thys van den Audenaerde, 1994; Lawrence Makasa, Fisheries Department Mpulungu, personal communication). However, this would not affect our conclusions about the maintenance of genetic and phenotypic diversity within Lake Chila.

We conducted a MCA based on nuptial colour traits of males to compare phenotypic diversity between different Pseudocrenilabrus populations. This analysis (and the MCA on the Lake Chila population only) did not result in the clustering of males with respect to mtDNA lineage assignment or any pattern that would indicate the presence of distinct morphs, but suggested a rather extensive colour pattern variation within the Lake Chila population, distinct from the other populations included in the analysis (Fig. 2A). Note, however, that males from Lake Chila that share the less frequent mtDNA haplotype with fish from the Uningi Pans (Ht32) showed a distinct phenotype (Fig. 2A), further rejecting an association between mtDNA lineage and nuptial colour pattern. The MCA separated blue and yellow morphs from the Lunzua
River and revealed differences in nuptial colouration, although with overlapping distributions, among some of the included populations (e.g. Lake Mweru-Wantipa, Lake Chila and Lunzua River, see Fig. 2A).

The CVA on body shape detected significant population differentiation for all analysed populations, with the lacustrine populations from Lakes MweruWantipa and Chila having shorter heads and deeper bodies compared to the riverine populations (Fig. 2B), indicating adaptation to different flow regimes in lake and riverine habitat (Webb, 1984). The PCA on the Lake Chila population did not reveal clustering of distinct phenotypes, rejecting the idea of eco-morphological divergence within the small lake. However, due to the bias in sample sizes of lake and stream populations, we cannot exclude that phenotypic variability of some of the included riverine populations may be underestimated.

In addition to a lack of discrete colour morphs within Lake Chila, the population assignment test with STRUCTURE (based on both datasets with 5 and 6 microsatellite loci) indicated no genetic substructure within the lake (Fig. 3), suggesting complete admixture between the two divergent mtDNA haplotype clades (the STRUCTURE analysis did infer distinct genetic clusters for Lake Chila and the populations from Lunzua River and Mbulu Creek; see Fig. 3).

Introgressive hybridisation between lineages has been proposed to facilitate the colonisation of new environments by increasing genetic variation and generating unique phenotypes via transgressive segregation (Kolbe et al., 2004; Seehausen, 2004). Such a genetically admixed 'hybrid swarm' often exceeds morphospace occupation when compared to parental populations (Lucek et al., 2010; Tobler \& Carson, 2010). Thus, selection can act on a broadened working surface and new, adaptive trait combinations may enable the exploitation of previously not utilized niches (Seehausen, 2004).

Stelkens \& Seehausen (2009) discovered two divergent mtDNA lineages in Lake Mweru, a rather large lake $150 \mathrm{~km}$ west of the southern end of LT (see Fig. 1). In Lake Mweru, one of the mitochondrial lineages was present in several distinct morphs (the study reports 'at least 13 distinct phenotypes'), whereas the other mtDNA lineage was represented by a single generalist phenotype only, and appeared to be generally very rare. The level of reproductive isolation between these morphs has been shown to 
correlate positively with divergence in nuptial colour pattern and eco-morphological divergence, but not with genetic differentiation (Stelkens \& Seehausen, 2009). Lake Mweru is much larger (131 km long and $56 \mathrm{~km}$ wide) and deeper (max. $27 \mathrm{~m}$ deep) than Lake Chila, and diversification in Lake Chila might be impeded due to the comparative long-term instability of the lake and the presumed recency (assuming that the Kafue-Zambezi haplotypes in Lake Chila result from unintentional stocking) of the admixture between the two distinct genetic lineages.

Given the small radiation in Lake Mweru, and the phenotypic and genetic variability in Lake Chila, it is puzzling why Pseudocrenilabrus did not diversify in any of the other lakes of the region despite its presence in most of the basins (Seehausen, 2006; Stelkens \& Seehausen, 2009).

During several sampling trips to rivers draining into southern LT (Kalambo, Lunzua and Lufubu), we observed that Pseudocrenilabrus were present in the more upstream regions of these rivers, whereas the dominant cichlid species in the downstream areas was Astatotilapia burtoni. We never found the two species in sympatry in any of the rivers (see also Seegers, 1996; Theis et al., unpublished). In Lake Chila, however, the two species co-occur, although Pseudocrenilabrus are much more abundant and we only caught $A$. burtoni in very low numbers and in a restricted area. Further, A. burtoni were smaller in body size and less intensively coloured compared to populations from LT or inflowing rivers (Theis et al., unpublished). Lake Chila is located 1,600 m above sea level and Pseudocrenilabrus cf. philander is known to be tolerant to temperatures as low as $16{ }^{\circ} \mathrm{C}$ (Loiselle, 1982). It seems that under these conditions, $P$. cf. philander is able to compete against the apparently less temperature-tolerant $A$. burtoni. Competitive exclusion of the two generalist species in combination with differing temperature tolerance might also explain the mutually exclusive distribution ranges of A. burtoni and $P$. philander in Zambian rivers. Lake Mweru, to our knowledge, does not harbour any 'modern' haplochromine species, which could partly explain why Pseudocrenilabrus successfully utilized the provided ecological opportunities in this lake (Stelkens \& Seehausen, 2009).

Our extended dataset on the $P$. philander species complex also provides new insights into the phylogeographic relationships of the genus. Overall, our mitochondrial phylogenetic reconstruction is largely in line with previous phylogenies from Katongo et al. (2005) and Koblmüller et al. (2012). However, an even more complex phylogeographic pattern emerges with the inclusion of additional samples. Our samples from the Lufubu River, which were assigned to $P$. sp. 'Lufubu A', grouped together with sequences from the most basal Pseudocrenilabrus lineage (Koblmüller et al., 2012; Fig. 4). The remaining taxa formed two major mitochondrial clades, one representing the Zambezi-Kafue drainage, and the other representing a lineage of mainly Congolese origin (see Figs. 1 and 4). The new samples from the Upper Luapula area (locations 19 and 20) were placed within the Zambezi-Kafue clade, indicating past connections of the Kafue/Zambezi and Chambeshi watersheds-in line with the presumed Zambezian influences of the ecoregion's ichthyofauna (Jackson, 1961, 1986; Balon, 1977; Scott, 2005). However, other specimens from locations 7, 10 and 11, which are part of the Chambeshi drainage, clustered with samples from Lake Mweru and Lake Mweru-Wantipa, which are part of the Congo drainage. The Bangweulu-Chambeshi subregion is known to harbour ichthyofaunal elements from both the Zambezi and Congo (Van Steenberge et al., 2014), and our phylogenetic inference demonstrates the occurrence of two mitochondrial lineages in the subregion, one belonging to the Zambezian and the other to the Congo drainage Pseudocrenilabrus clades. These phylogeographic patterns are in line with previous studies on other cichlid species (Joyce et al., 2005; Katongo et al., 2007) and African tigerfish (Goodier et al., 2011), all of which imply repeated and fairly recent faunal exchange between the Zambezi and Zambian Congo system by capture of entire river systems as well as small headwater creeks, despite the longstanding separation of the main courses (Stankiewizc \& de Wit, 2006; Cotterill \& de Wit, 2011).

The second Pseudocrenilabrus lineage found in the Lufubu, $P$. sp. 'Lufubu B', was placed as sister group to the Chambeshi clade, indicating a second wave of colonisation of the Lufubu river via the upper Congo system by a derived haplotype lineage (see also Koblmüller et al., 2012). Moreover, sequences from fish collected in Lake Chilwa and Nkhotakota/LM were resolved in this clade, which suggests a past connection between the upper Malawi and Chambeshi drainages, possibly via the Luangwa (note that 
specimens from the Luangwa, Nsefu Lagoon also grouped in the same clade, Figs. 1, 4; see also Tweddle $\&$ Skelton, 2008).

Our specimens from the Lunzua River and Mbulu Creek all shared a single mitochondrial haplotype with previously published sequences (Koblmüller et al., 2008b, 2012) and were resolved, although weakly supported, as sister to the Zambezi clade. The dispersal route of this haplotype between the Lunzua River and Mbulu Creek is puzzling, given that the Uningi Pans, which contain a different haplotype, are located in between both river's headwaters (see Figs. 1, 4). The Lunzua and Mbulu, however, might have been connected downstream during a severe low surface level in LT (the two rivers enter LT in the Chituta Bay; McGlue et al., 2008)—or alternatively, gene flow between the two streams might have been enabled via past river capture of small headwaters. The two populations did show genetic differentiation at nuclear markers, as evidenced by significant pairwise $\theta_{\mathrm{ST}}$ values (Table 1). We also detected genetic differentiation between the two sampling locations in Lunzua from 2010 and interestingly, also between specimens sampled from the same location in the years 2004 and 2010, corroborating the idea that genetic bottlenecks induced by strong seasonal variation of flood plains and small river confluences have a strong impact on the population dynamics of cichlid fish in general and on Pseudocrenilabrus in particular (Koblmüller et al., 2008b; Crispo \& Chapman, 2010; Hermann et al., 2011). In contrast to Koblmüller et al. (2008b), blue and yellow morphs (both in 2004 and 2010) were not genetically differentiated (Table 1), which might be explained by the use of a different set of microsatellite markers.

Taken together, our study reveals a rather complex phylogeographic pattern and demonstrates introgression between distant mitochondrial lineages in a basal haplochromine cichlid, providing additional evidence for the role of hybridisation in the evolution of haplochromines (Joyce et al., 2011; Schwarzer et al., 2012). The occurrence of divergent mtDNA haplotypes and extensive morphological variation in Lake Chila, together with the small radiation in Lake Mweru, which contrast the low genetic and phenotypic diversity found in rivers, suggest that Pseudocrenilabrus are more prone to diversify in a lake habitat providing more ecological opportunity, especially when more derived 'modern' haplochromines are absent. That Pseudocrenilabrus did not (yet) diversify further in Lake Chila might be related to the small size and hence comparative long-term instability of Lake Chila and the presumed recency of the admixture between the two distinct genetic lineages.

Acknowledgments We would like to thank our helpers in the field, J. Bachmann, T. Bosia and L. Schild, the Kasanka Trust, the Lake Tanganyika Research Unit, Department of Fisheries, Republic of Zambia, for research permits and Radim Blazek and Martin Reichard for providing samples. This study was supported by grants from the European Research Council (ERC, Starting Grant 'INTERGENADAPT'), the University of Basel, and the Swiss National Science Foundation (SNF, Grant 3100A0_138224) to W. S.

\section{References}

Balon, E. K., 1977. The golden mudsuckers (Labeo spp.) from above and below the Victoria Falls: Sibling species along different invasion routes. Hydrobiologia 53: 3-12.

Bruford, M. W., O. Hanotte, J. F. Y. Brookfield \& T. Burke, 1998. Multilocus and single-locus DNA fingerprinting; molecular genetic analysis of populations, a practical approach. In Hoelzel A. R. (eds), Oxford University Press, Oxford: $287-336$.

Cotterill, F. P. D. \& M. J. de Wit, 2011. Geoecodynamics and the Kalahari epeirogeny: linking its genomic record, tree of life and palimpsest into a unified narrative of landscape evolution. South African Journal of Geology 114: 489-514.

Crispo, E., C. Hagen, T. Glenn, G. Geneau \& L. J. Chapman, 2007. Isolation and characterization of tetranucleotide microsatellite markers in a mouth-brooding haplochromine cichlid fish (Pseudocrenilabrus multicolor victoriae) from Uganda. Molecular Ecology Notes 7: 1293-1295.

Crispo, E. \& L. J. Chapman, 2010. Temporal variation in population genetic structure of a riverine African cichlid fish. Journal of Heredity 101: 97-106.

Duftner, N., S. Koblmüller \& C. Sturmbauer, 2005. Evolutionary relationships of the Limnochromini, a tribe of benthic deep water cichlid fishes endemic to Lake Tanganyika. Journal of Molecular Evolution 60: 277-289.

Earl, D. A. \& B. M. von Holdt, 2012. STRUCTURE HARVESTER: a website and program for visualizing STRUCTURE output and implementing the Evanno method. Conservation Genetics Resources 4: 359-361.

Evanno, G., S. Regnaut \& J. Goudet, 2005. Detecting the number of clusters of individuals using the software STRUCTURE: a simulation study. Molecular Ecology 14: 2611-2620.

Excoffier, L. \& H. E. L. Lischer, 2010. Arlequin suite ver 3.5: a new series of programs to perform population genetics analyses under Linux and Windows. Molecular Ecology Resources 10: 564-567.

Goodier, S. A. M., F. P. D. Cotterill, C. O’Ryan, P. H. Skelton \& M. J. de Wit, 2011. Cryptic diversity of African tigerfish (genus Hydrocynus) reveals palaeogeographic signatures 
of linked neogene geotectonic events. PLOS One 6: e28775.

Greenwood, P. H., 1989. The taxonomic status and phylogenetic relationships of Pseudocrenilabrus Fowler (Teleostei, Cichlidae). Ichthyological Bulletins of the J. L. B. Smith Institute of Ichthyology 54: 1-16.

Hermann, C. M., K. M. Sefc \& S. Koblmüller, 2011. Ancient origin and recent divergence of a haplochromine cichlid lineage from isolated water bodies in the East African Rift system. Journal of Fish Biology 79: 1356-1369.

Husson, F., J. Josse, S. Le \& J. Mazet, 2014. FactoMineR: multivariate exploratory data analysis and data mining with R. R package version 1: 26.

Jackson, P. B. N., 1961. The fishes of Northern Rhodesia. The government printer, Lusaka: 140.

Jackson, P. B. N., 1986. Fish of the Zambezi system. In Davies, B. R. \& K. F. Walker (eds), The ecology of river systems. W. Junk, Dordrecht: 269-288.

Joyce, D. A., D. H. Lunt, R. Bills, G. F. Turner, C. Katongo, N. Duftner, C. Sturmbauer \& O. Seehausen, 2005. An extant cichlid fish radiation emerged in an extinct Pleistocene lake. Nature 435: 90-95.

Joyce, D. A., D. H. Lunt, M. J. Genner, G. F. Turner, R. Bills \& O. Seehausen, 2011. Repeated colonization and hybridization in Lake Malawi cichlids. Current Biology 21: R108-R109.

Katoh, K., K. Misawa, K. Kuma \& T. Miyata, 2002. MAFFT: a novel method for rapid multiple sequence alignment based on fast Fourier transform. Nucleic Acids Research 30: 3059-3066.

Katongo, C., S. Koblmüller, N. Duftner, L. Makasa \& C. Sturmbauer, 2005. Phylogeography and speciation in the Pseudocrenilabrus philander species complex in Zambian rivers. Hydrobiologia 542: 221-233.

Katongo, C., S. Koblmüller, N. Duftner, L. Mumba \& C. Sturmbauer, 2007. Evolutionary history and biogeographic affinities of the serranochromine cichlids in Zambian rivers. Molecular Phylogenetics and Evolution 45: 326-338.

Kellogg, K. A., J. A. Markert, J. R. Stauffer \& T. D. Kocher, 1995. Microsatellite variation demonstrates multiple paternity in lekking cichlid fishes from Lake Malawi, Africa. Proceedings of the Royal Society B 260: 79-84.

Klingenberg, C. P., 2011. MorphoJ: an integrated software package for geometric morphometrics. Molecular Ecology Resources 11: 353-357.

Koblmüller, S., U. K. Schliewen, N. Duftner, K. M. Sefc, C. Katongo \& C. Sturmbauer, 2008a. Age and spread of the haplochromine cichlid fishes in Africa. Molecular Phylogenetics and Evolution 49: 153-169.

Koblmüller, S., K. M. Sefc, N. Duftner, C. Katongo, T. Tomljanovic \& C. Sturmbauer, 2008b. A single mitochondrial haplotype and nuclear genetic differentiation in sympatric colour morphs of a riverine cichlid fish. Journal of Evolutionary Biology 21: 362-367.

Koblmüller, S., W. Salzburger, B. Obermüller, E. Eigner, C. Sturmbauer \& K. M. Sefc, 2011. Separated by sand, fused by dropping water: habitat barriers and fluctuating water levels steer the evolution of rock-dwelling cichlid populations in Lake Tanganyika. Molecular Ecology 20: 2272-2290.
Koblmüller, S., C. Katongo, H. Phiri \& C. Sturmbauer, 2012. Past connection of the upper reaches of a Lake Tanganyika tributary with the upper Congo drainage suggested by genetic data of riverine cichlid fishes. African Zoology 47: 182-186.

Kocher, T. D., 2004. Adaptive evolution and explosive speciation: The cichlid fish model. Nature Reviews Genetics 5: 288-298.

Kolbe, J. J., R. E. Glor, L. R. G. Schettino, A. C. Lara, A. Larson \& J. B. Losos, 2004. Genetic variation increases during biological invasion by a Cuban lizard. Nature 431: 177-181.

Lee, W. J., J. Conroy, W. H. Howel \& T. D. Kocher, 1995. Structure and evolution of teleost mitochondrial control regions. Journal of Molecular Evolution 41: 54-66.

Loiselle, P. V., 1982. Pseudocrenilabrus; the dwarf African mouthbrooders, part one: the Pseudocrenilabrus multicolor complex. Freshwater and Marine Aquarium 51(30-35): 59-63.

Lucek, K., D. Roy, E. Bezault, A. Sivasundar \& O. Seehausen, 2010. Hybridization between distant lineages increases adaptive variation during a biological invasion: stickleback in Switzerland. Molecular Ecology 19: 3995-4011.

Mardia, K. V., J. Kent \& J. Bibby, 1979. Multivariate analysis. Academic Press, New York.

Maeda, K., H. Takeshima, S. Mizoiri, N. Okada, M. Nishida \& H. Tachida, 2008. Isolation and characterization of microsatellite loci in the cichlid fish in Lake Victoria, Haplochromis chilotes. Molecular Ecology Resources 8: 428-430.

Matschiner, M. \& W. Salzburger, 2009. TANDEM: integrating automated allele binning into genetics and genomics workflows. Bioinformatics 25: 1982-1983.

Meyer, A., J. M. Morrissey \& M. Schartl, 1994. Recurrent origin of a sexually selected trait in Xiphophorus fishes inferred from a molecular phylogeny. Nature 368: 539-541.

McGlue, M. M., K. E. Lezzar, A. S. Cohen, J. M. Russell, J. J. Tiercelin, A. A. Felton, E. Mbede \& H. H. Nkotagu, 2008. Seismic records of late Pleistocene aridity in Lake Tanganyika, tropical East Africa. Journal of Paleolimnology 40: 635-653.

Muschick, M., A. Indermaur \& W. Salzburger, 2012. Convergent Evolution within an Adaptive Radiation of Cichlid Fishes. Current biology 22: 2362-2368.

Poll, M., 1967. Contribution à la faune ichthyologique de l'Angola. Publicações. Culturais da Companhia de Diamantes Angola 75: 1-381.

Posada, D., 2008. jModelTest: Phylogenetic model averaging. Molecular Biology and Evolution 25: 1253-1256.

Pritchard, J. K., M. Stephens \& P. Donnelly, 2000. Inference of population structure using multi-locus genotype data. Genetics 155: 945-959.

R Core Team, 2014. R: A language and environment for statistical computing. R Foundation for Statistical Computing, Vienna, Austria. ISBN 3-900051-07-0, URL http:// www.R-project.org/.

Rambaut A., M. A. Suchard, D. Xie \& A. J. Drummond, 2013. Tracer v1.6. http://beast.bio.ed.ac.uk/Tracer.

Rohlf, F. J., 2008. TPSDIG, Version 2.11. Department of Ecology and Evolution, State University of New York at 
Stony Brook, Stony Brook. http://life.bio.sunysb.edu/ morph/.

Rohlf, F. J. \& D. E. Slice, 1990. Extensions of the Procrustes method for the optimal superimposition of landmarks. Systematic Zoology 39: 40-59.

Ronquist, F., Teslenko, M., van der Mark, P., Ayres, D. L., Darling, A., Hohna, S., Larget, B., Liu, L., M. A. Suchard \& J. P. Huelsenbeck, 2012. MrBayes 3.2: efficient Bayesian phylogenetic inference and model choice across a large model space. Systematic Biology 61: 539-542.

Salzburger, W., 2009. The interaction of sexually and naturally selected traits in the adaptive radiations of cichlid fishes. Molecular Ecology 18: 169-185.

Salzburger, W., T. Mack, E. Verheyen \& A. Meyer, 2005. Out of Tanganyika: Genesis, explosive speciation, key-innovations and phylogeography of the haplochromine cichlid fishes. BMC Evolutionary Biology 5: 17.

Salzburger, W., H. Niederstätter, A. Brandstätter, B. Berger, W. Parson, J. Snoeks \& C. Sturmbauer, 2006. Color-assortative mating in the cichlid species Tropheus moorii from Lake Tanganyika, East Africa. Proceedings of the Royal Society London B-Biological Sciences 273: 257-266.

Santos, M. E. \& W. Salzburger, 2012. How cichlids diversify. Science 338: 619-621.

Schwarzer, J., E. R. Swartz, E. Vreven, J. Snoeks, F. P. D. Cotterill, B. Misof \& U. K. Schliewen, 2012. Repeated trans-watershed hybridization among haplochromine cichlids (Cichlidae) was triggered by Neogene landscape evolution. Proceedings of the Royal Society B 279: 4389-4398.

Schluter, D., 2000. The ecology of adaptive radiation. Oxford University Press, New York.

Scott, L., 2005. Bangweulu-Mweru. In M. L. Thieme, R. Abell, M. L. Stiassny, P. Skelton, B. Lehner, E. Dinerstein, G. G. Teugels, N. Burgess, A. K. Toham \& D. Olson (eds), Freshwater ecoregions of Africa and Madagascar: a conservation assessment. Island Press, New York: 185-186.

Seegers, L., 1996. The fishes of the Lake Rukwa drainage. Annales du Musée royal de l'Afrique Centrale. Sciences zoologiques, Tervuren.

Seehausen, O., 2004. Hybridization and adaptive radiation. Trends in Ecology and Evolution 19: 198-207.

Seehausen, O., 2006. African cichlid fish: a model system in adaptive radiation research. Proceedings of the Royal Society B 273: 1987-1998.

Skelton, P. H., 1991. Pseudocrenilabrus. In Daget, J., J. P. Gosse, G. G. Teugels \& D. F. E. T. van den Audenaerde (eds), Check-list of freshwater fishes of Africa (CLOFFA). ISNB, Brussels; MRAC, Tervuren; and ORSTOM, Paris, 4: 394-398.

Skelton, P. H., 1993. Scientific and common names of southern African freshwater fishes. J. L. B. Smith Institute of Ichthyology, Grahamstown:1-34.

Skelton, P. H., 1994. Diversity and distribution of freshwater fishes in East and Southern Africa. Annales du Musée de la
République de l'Afrique Centrale, Zoologique 275: 95-131.

Stankiewics, J. \& M. de Wit, 2006. A proposed drainage evolution model for Central Africa-did the Congo flow east? Journal of African Earth Sciences 44: 75-84.

Stelkens, R. B. \& O. Seehausen, 2009. Phenotypic divergence but not genetic distance predicts assortative mating among species of a cichlid fish radiation. Journal of Evolutionary Biology 22: 1679-1694.

Taylor, M., F. Meardon, G. F. Turner, O. Seehausen, H. Mrosso \& C. Rico, 2002. Characterization of tetranucleotide microsatellite loci in a Lake Victorian, haplochromine cichlid fish: a Pundamilia $\times$ Pundamilia nyererei hybrid. Molecular Ecology Notes 2: 443-445.

Thys van den Audenaerde, D. F. E., 1994. Introduction of aquatic species into Zambian waters, and their importance for aquaculture and fisheries. Aquaculture for Local Community Development Programme, field document no. 24.

Tobler, M. \& E. W. Carson, 2010. Environmental variation, hybridization, and phenotypic diversification in Cuatro Ciénegas pupfishes. Journal of Evolutionary Biology 23(7): 1475-1489.

Turner, G. F., O. Seehausen, M. E. Knight, C. J. Allender \& R. L. Robinson, 2001. How many species of cichlid fishes are there in African lakes? Molecular Ecology 10: 793-806.

Tweddle, D. \& P. H. Skelton, 2008. New species of 'Barbus' and Labeobarbus (Teleostei: Cyprinidae) from the South Rukuru River, Malawi, Africa. Smithiana Bulletin 8: 25-39.

Twentyman-Jones, V., A. J. Ribbink \& D. Voorvelt, 1997. Colour clues to incipient speciation of Pseudocrenilabrus philander (Teleostei, Cichlidae). South African Journal of Science 93: 529-537.

Van Oppen, M. J. H., Rico C., Deutsch, J. C., G. F. Turner \& G. M. Hewitt, 1997. Isolation and characterization of microsatellite loci in the cichlid fish Pseudotropheus zebra. Molecular Ecology 6: 387-388.

Van Steenberge, M., E. Vreven \& J. Snoeks, 2014. The fishes of the Upper Luapula area (Congo basin): a fauna of mixed origin. Ichthyological Exploration of Freshwaters 24: 289-384.

Verheyen, E., W. Salzburger, J. Snoeks \& A. Meyer, 2003. On the origin of the superflock of cichlid fishes from Lake Victoria, East Africa. Science 300: 325-329.

Villesen, P., 2007. FaBox: an online toolbox for fasta sequences. Molecular Ecology Notes 7: 965-968.

Wagner, C. E., L. J. Harmon \& O. Seehausen, 2012. Ecological opportunity and sexual selection together predict adaptive radiation. Nature 487: U124-U366.

Webb, P., 1984. Body form, locomotion and foraging in aquatic vertebrates. American Zoologist 24: 107-120.

Weir, B. \& C. C. Cockerham, 1984. Estimating F-statistics for the analysis of population structure. Evolution 38: 1358-1370. 